Chapman University

Chapman University Digital Commons

$4-2020$

\title{
A Test of the Modigliani-Miller Theorem, Dividend Policy and Algorithmic Arbitrage in Experimental Asset Markets
}

Tibor Neugebauer

Jason Shachat

Wiebke Szymczak

Follow this and additional works at: https://digitalcommons.chapman.edu/esi_working_papers

Part of the Econometrics Commons, Economic Theory Commons, and the Other Economics Commons 
A Test of the Modigliani-Miller Theorem, Dividend Policy and Algorithmic Arbitrage in Experimental Asset Markets

Comments

ESI Working Paper 20-14 


\title{
A test of the Modigliani-Miller theorem, dividend policy and algorithmic arbitrage in experimental asset markets
}

\author{
Tibor Neugebauer,; Jason Shachat ${ }^{\dagger}$ and Wiebke Szymczak ${ }^{\ddagger}$
}

April 2020

\begin{abstract}
Modigliani and Miller showed that the market value of the company is independent of its capital structure, and suggested that dividend policy makes no difference to this law of one price. We experimentally test the MM theorem in a complete market with two simultaneously traded assets, employing two experimental treatment variations. The first variation involves the dividend stream. According to this variation the dividend payout order is either identical or independent. The second variation involves the market participation, or not, of an algorithmic arbitrageur. We find that Modigliani-Miller's law of one price can be supported on average with or without arbitrageur when dividends are identical. The law of one price breaks down when dividend payout order is independent unless the arbitrageur keeps the asset prices in balance.
\end{abstract}

JEL codes: C92, G32, G35

keywords:Modigliani-Miller, arbitrage, dividends, experiment, asset market

\footnotetext{
*University of Luxumbourg

${ }^{\dagger}$ Durham University and Wuhan University

$\ddagger$ University of Hamburg
} 


\section{Introduction}

We report an experimental test of the Modigliani-Miller value-invariance theorem of capital structure and the sensitivity of the value-invariance proposition to dividend payout variations. Modigliani and Miller (1958) showed by arbitrage proof with perfectly correlated cash flows that the capital structure is irrelevant for the market value of the firm. An early criticism of this law of one price was the challenging question of market response to dividend payout decisions (Durand 1959, Modigliani and Miller 1959). Real-world dividends are declared by the board of directors. A remaining question is whether the Modigliani-Miller theorem holds if "man-made" dividend policies are not perfectly correlated along with the underlying cash flows. If value invariance breaks down with variations in dividend policies, the empirical relevance of "the value-invariance proposition would seem to be narrow" (see Miller 1988, p. 103f).

The second Modigliani-Miller theorem, the dividend irrelevance theorem (Miller and Modigliani 1961), was developed to address this question. The market valuation depends on the firm's dividends in the following way. The more the investor gets in dividend payments, the less she gets in capital appreciation and vice versa. An investor should be indifferent between dividend payouts and price appreciation, and thus the value of the firm is independent of the dividend policy. Different from the earlier contribution where arbitrage implies value-invariance, however, Miller and Modigliani (1961) left open the question of how the market would approach equilibration in the dividend irrelevance theorem. Empirical analyses of dividendpayout policies suggest that dividend payouts are not independent of the market value of the firm (Angelo and Angelo 2006; Asparouhova, Besliu and Lemmon 2016).

In this paper we propose another empirical test of the dividend irrelevance hypothesis under controlled laboratory conditions. We test the law of one price in the laboratory with two simultaneously traded assets, the cash flows of which are perfectly correlated. The two assets pay four regular dividend amounts which are known from the beginning, but the order of the dividend payouts is random. After the last regular dividend payment each asset pays a random liquidation dividend. It is a complete market setting. The liquidation dividends of the assets differ by a constant amount; thus, the sum of cash flows are perfectly correlated.

We investigate two experimental treatment variations in a two-by-two design. The first treatment condition varies the regular dividend streams prior to the liquidation dividend. According to this variation the dividend order of the two assets is identical or independent. When the order of dividends is identical, we have one regular dividend draw without replacement for both assets in every period. When 
the order of dividends is independent, the regular dividends of the assets are independent draws without replacement. We test the question whether the law of one price holds with identical and with different dividend policies. The identical dividend payout order implies a narrow test of the Modigliani-Miller (1958) value-invariance theorem of the law of one price, whereas the independent dividend order implies a test of the broader implication including the irrelevance of dividend payouts. Since the difference between liquidation dividends is known with certainty and the sum of remaining dividend payments is also known with certainty, any price discrepancies offers an arbitrage opportunity. The second treatment condition varies the market participation of an algorithmic arbitrageur. In one variation there is no algorithm, and there is one in the other. Based on the potential price discrepancies in the market we test the MM law of one price with and without arbitrageur.

According to our data, differences in dividend payouts impact market prices of equivalent assets. Our data suggest that with an identical order of dividend payouts, value-invariance can be supported on average. When the orders of dividend payouts are independent, however, value-invariance seems to break down in absence of the algorithmic arbitrageur. Only in presence of the algorithmic arbitrageur we can support the MM law of one price on average if dividend payouts are independent. Arbitrageurs help the market to reinstate the law of one price on average in our data. That said, the result is on the average only. Throughout the experiment, arbitrage opportunities do not completely disappear and, thus, pricing discrepancies between the two assets remain. Hence, our data do not support the law of one price in real time or on the level of average price in a period. This result occurs in all treatments if the algorithmic arbitrageur is present or not. In this study we also look at the pricing of assets relative to fundamental value. We find substantial deviations from fundamental dividend values. The algorithmic arbitrageur seems to have no impact on these deviations.

Our study contributes to the growing body of experimental work on financial markets, in particular to the line of research that investigates the effects of algorithmic trading in markets and, on the other hand, to the research contributing to the understanding of the Modigliani-Miller theorem and arbitrage. The experimental finance literature on algorithmic trading includes approaches to randomized algorithms ("zero intelligence traders" of Gode and Sunder 1993), behavioral aversion effects to trading with algorithms (Farjam and Kirchkamp 2017; Leal and Hanaki 2018; Angerer, Neugebauer and Shachat 2019), efficiency of market institution and high frequency trading (Aldrich and López Vargas forthcoming), competitions of subjectchosen algorithms (Asparouhova, Bossaerts, Rotaru, Wang, Yadav and Yang 2019), 
and, finally, arbitrage algorithms (Rietz 2005; Angerer et al 2019). $1^{1}$ The experimental literature on the Modigliani-Miller theorem of the law of one price includes studies of single-asset pricing (Levati, Qiu and Mahganokar 2012) and pricing of perfectly correlated twin assets (Asparouhova et al. 2016; Charness and Neugebauer 2019, Angerer, Neugebauer and Shachat 2019). The latter studies are closely related to ours.

Charness and Neugebauer (2019) show that Modigliani-Miller's law of one price holds on average in repeated experimental asset markets with a declining fundamental value when cash flows are perfectly correlated. Charness and Neugebauer study an experimental asset market in which the dividends of the two shares are always identical modulo a shift. The study confirms the law of one price on average despite the fact that subjects do not exploit arbitrage opportunities as suggested in the underlying theory (Modigliani and Miller 1958). On a more detailed level of analysis, similar to our results, Charness and Neugebauer reject the law of one price on the period level as they find that pricing discrepancies never disappear even in the repeated market setting. Angerer et al. (2019) study different arbitrageur strategies with algorithms in the experimental design of Charness and Neugebauer. The study shows that market quality vis-à-vis the law of one price is clearly enhanced when an arbitrageur acts in the market. On the period level, yet, the data in Angerer et al. still suggest failure of the law of one price even when the arbitrageur is present, since average prices deviate from parity.

Asparouhova et al. (2016) study a two-period design in which two assets pay the same sum of dividends but in different timely orders. In their setting, and in contrast to our design, they induce different preferences for cash and cash dividends between investor subjects. Their data suggest that, possibly as a consequence of subjects' cash preferences, the asset that pays the early dividend is priced at a premium relative to the asset that pays the late dividend. Thus, Asparouhova et al. reject the ModiglianiMiller theorem. Similarly to Asparouhova et al. and different from Charness and Neugebauer, and Angerer et al., the assets in our experimental design pay a fixed sum of dividends plus a random liquidation payment. Similarly to Angerer et al., the presence of an arbitrageur algorithm is varied in one treatment condition of our study. Different from these three studies, our second treatment condition varies

\footnotetext{
${ }^{1}$ Hence, we also contribute to the small body of experimental literature on arbitrage in markets (O'Brien and Srivastava 1991; Abbink and Rockenbach 2006; Bossaerts, Shachat and Xie 2018). Bossaerts et al. (2018) is an important reference for us, because our experimental design implements a two-asset variation of their design. Their design involves a single asset that is traded for 5 periods and that pays a dividend at the end of each period which is drawn without replacement from a set of five known dividends.
} 
the complexity of dividend streams across the two assets. We find that ModiglianiMiller's law of one price can be supported on average with or without arbitrageur when the same dividend policy is induced. When the dividend policy varies between assets, however, the law of one price breaks down unless an algorithmic arbitrageur helps to keep prices in balance.

The paper is organized as follows. We start by presenting the experimental design in the Section 2, before we briefly discuss the theory and the testable hypotheses in Section 3. Section 4 reports the data, and Section 5 concludes.

\section{Experimental design}

The experimental session is organized in six market sequences. Each market sequence lasts for four periods involving one cohort of eight subjects; see the timeline of a market sequence in Figure1. At the beginning of the sequence, subjects are endowed with 4,000 cash units and five shares of two assets from the same risk class. We refer to these assets as "the L-share" and "the U-share", respectively $\left.\right|^{2}$ At the end of the period, each asset pays a cash dividend from the set of $-50,-50,+50,+50$ cash units. The cash dividends are drawn without replacement, so that exactly two dividend payments are positive and the other two are negative. Dividend payments are added to the subject's cash balance, and shares and cash carry over to the next period. At the end of period 4, after four dividend payments, subjects receive a liquidation payment for each share. The liquidation payment of the L-share is either 100 or 300 cash units, both outcomes being equally likely. The liquidation payments are perfectly correlated; the liquidation payment of the U-share is 200 cash units higher than the one of the A-share. Following the liquidation payment, the subject's final cash balance is determined, and shares are cancelled. One of the six sequences is decisive for payment. Subjects are informed at the end of the session about the decisive sequence. Their final payment is equivalent to the final cash balance in the decisive sequence plus a lump-sum for participation.

It is crucial to note that the sum of regular dividends for each share is zero, and the sum of remaining dividends, which varies from period to period, is known with certainty for each asset always. The expected liquidation payment of the two shares differs by a constant, i.e., 200 cash units. Accounting for differences in the sum of remaining dividends and the liquidation payment differential, thus, any price discrepancies offer arbitrage opportunities, i.e., immediate riskless profits by selling

\footnotetext{
${ }^{2}$ With the L, U notation we refer to "levered" and "unlevered" equity. In the experiment, however, we refer to the A-share and the B-share, respectively.
} 


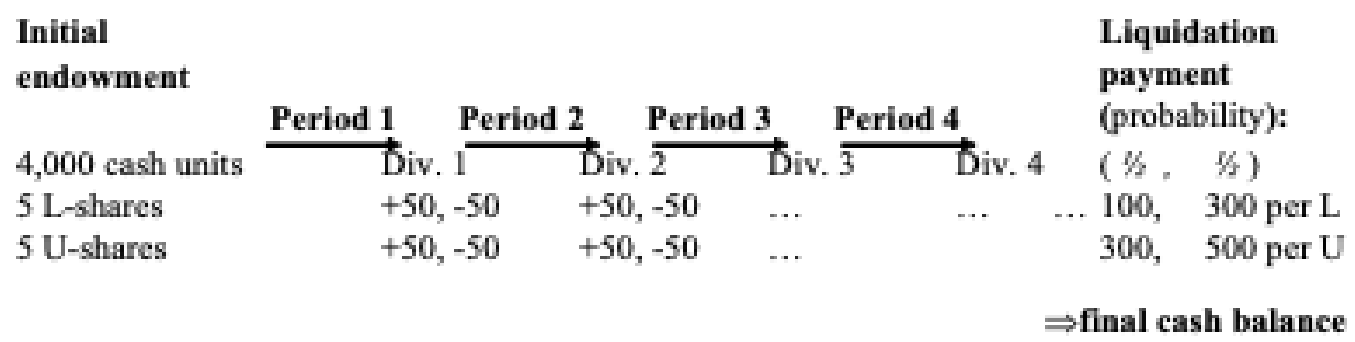

Figure 1: Timeline of experimental market sequence

high and buying low.

In each period, the market opens where the two assets can be traded in a continuous double auction. Subjects submit limit orders (i.e., bids and asks) or accept outstanding limit orders to close a transaction. Limit orders can be cancelled. Short sales and purchases on loan are enabled; the minimum cash balance is $-3,000$ cash units and the minimum holding of L-share and U-share is -5 each. Trading is free of submission and transaction fees and interest rate and short sale fees are zero. The trading time per period is three minutes in the first two market sequences and two minutes per period thereafter. During the market period subjects observe in real time the bids and asks in open order books and the market prices, including high, low, average and opening prices. The received dividends and the remaining dividends are announced throughout the sequence. Subjects see their cash balance, their share holdings, they have a record of all their transactions, dividend incomes during the market sequence.

Table 1: Treatment conditions and treatment names

\begin{tabular}{lcc}
\hline \multirow{2}{*}{ Dividend streams } & \multicolumn{2}{c}{ Algorithm participation } \\
\cline { 2 - 3 } & No algorithm & Arbitrage algorithm \\
\hline Identical dividends & OneUrn/NoBot & OneUrn $/$ Bot \\
Independent dividends & TwoUrn/NoBot & TwoUrn $/$ Bot \\
\hline
\end{tabular}

The experiment varies two treatment conditions in a $2 \times 2$ design; see Table 1 . The treatments differ with respect to the dividend sequence (one-urn or two-urn variation) and the participation of the algorithm in the market (no-bot or bot variation). If the dividend sequence of the two assets is identical (i.e., the one-urn condition), the dividends of the A-share and the B-share are the same in each period. If the sequences are independent (i.e., the two-urn condition), the sequence of dividends are drawn independently for the L-share and U-share. When the algorithm participates (i.e., 
the bot condition), every arbitrage opportunity is instantaneously and automatically exploited in real-time upon submission (equivalent to the fast bot in Angerer et al. 2019). In all treatments we announce the possible participation of the algorithm, but we provide no information on the actual participation and on the the strategy of the algorithm to the experimental subjects.

Upon arrival at the laboratory, subjects were randomly seated in the laboratory. In each session, some cohorts were exposed to the arbitrage algorithm while other cohorts were not. The written instructions, which were tape recorded and played back, referred to the potential participation of the algorithm $3^{3}$ Each subject participated in exactly one cohort of eight in exactly one experimental treatment. After having read the instructions, subjects interacted within their cohort in a practice session of three minutes. During the practice session, which never involved the participation of the algorithm, no interaction had any payoff consequence. The dividend sequences, liquidation values and payment decisive sequence were pre-drawn at once for all 32 cohorts on an spread-sheet and introduced into the software. The pre-drawing procedure was explained to subjects in the instructions. The pre-drawn random values were recorded on paper, put into an envelope placed at the wall of the laboratory. After the last sequence of the experiment, the envelope was opened and the prerecorded values were announced to subjects. Subjects could compare these values with the once of their experiment which were recorded on their computer screen. Thus, subjects were able to see that the instructor could not influence their personal payments. At the end of the experiment we debriefed subjects in a questionnaire, in which we collected socio-demographic data.

The experiment was computerized using zTree (Fischbacher 2007). For the recruitment of subjects we used ORSEE (Greiner 2015). The experimental sessions were conducted in the laboratory LEE at the University of Castellon in Spain. Our experiment consisted of thirty-two cohorts of eight subjects each. Exactly eight cohorts were randomly assigned to each of our four experimental treatment conditions.

\footnotetext{
${ }^{3}$ Farjam and Kirchkamp (2017) suggest that such announcement alone can lead to more efficient market prices. The potential participation of an algorithm could thus bias our data towards efficiency. However, one should note that Leal and Hanaki (2018) and Angerer, Neugebauer and Shachat (2019) found no announcement effect in market prices.
} 


\section{Theoretical consideration, measures and testable hypotheses}

\subsection{Theoretical considerations}

Modigliani and Miller (1958) showed that the market value of the corporation is invariant to its capital structure. Let $V_{U} \equiv S_{U}$ denote the market value of unlevered equity of the company. Let $V_{L}$ denote the market value of the levered company including the value of levered equity, $S_{L}$, and the (constant) market value of bonds, B. According to the Modigliani-Miller value-invariance theorem (without taxes), the market value of the company with or without debt is the same.

$$
V_{U} \equiv S_{U}=S_{L}+B \equiv V_{L}
$$

The crucial point of the arbitrage proof of the MM invariance theorem is that if the value of levered equity and the value of unlevered equity differ by more or less than the debt, the arbitrageur will sell the high-priced and buy the low-priced share of equity and make an arbitrage gain. In the (no-arbitrage) equilibrium, thus, the market value of levered equity and the market value of unlevered equity must differ by the value of bonds, i.e., $S_{U}-S_{L}=B$.

How does our experimental design map into the Modigliani-Miller world? In the experiment we assume a constant "synthetic value of debt" which can be thought of as being represented by the constant difference in liquidation payments of the L-share and U-share. In our setting, possible differences in the sum of remaining dividends add to or subtract from the differences in liquidation payments. We denote the sum of remaining dividend payments of L-share and U-share explicitly by $D_{L}$ and $D_{U}$, and $R_{L}$ and $R_{U}$ are the market values of the liquidation payments, where $S_{L} \equiv R_{L}+D_{L}$ and $S_{U} \equiv R_{U}+D_{U}$. Thus, value invariance in our experiment implies the following equation.

$$
V_{U} \equiv R_{U}+D_{U}=R_{U}+D_{U}+B \equiv V_{L}
$$

Equation (2) must be fulfilled in the no-arbitrage equilibrium, even with varying, independent dividend payouts. This equation is the starting point for our experimental tests.

\subsection{Measures}

In our analysis we apply (besides the measure of arbitrage value in real time) also the measures proposed in Charness and Neugebauer (2019). So, we measure deviations 
from the law of one price between the L-share and the U-share by the deviations from parity pricing (DPP). The measure is similar to the one formulated in Charness and Neugebauer (2019), where the time index indicates the period $\mathrm{t}=1,2,3$, 4, i.e.,

$$
D P P_{t}=\frac{S_{U, t}}{S_{L, t}+B}-1=\frac{\left(S_{U, t}-S_{L, t}\right)-\Delta F V_{t}}{S_{L, t}+\Delta F V_{t}}
$$

$\Delta F V_{t} \equiv F V_{U, t}-F V_{L, t}$ is the difference in remaining payouts between shares, where $F V_{L, t}$ and $F V_{U, t}$ denote the sum of remaining dividends plus expected liquidation payment of L-share and U-share, respectively. We measure the average deviation from parity pricing per period over the course of one market sequence as follows.

$$
D P P=\frac{1}{T} \sum_{t=1}^{T} D P P_{t}
$$

Deviations from parity pricing can average zero, although deviations from parity pricing always exist. Therefore, we measure the average absolute deviation from parity pricing (ADPP) between the L-share and U-share as follows.

$$
A D P P=\frac{1}{T} \sum\left|D P P_{t}\right|
$$

ADPP denotes the average absolute deviation from parity pricing during the course of a market sequence. If average prices in a period equal dividend value, or if the average prices differ by dividend value the ADPP measure is zero. Indeed even with zero ADPP measure, average prices can deviate from fundamental dividend values.

Even if $\mathrm{ADPP}=0$, it can be that many arbitrage opportunities arise in the course of trading. Therefore, we measure (potential) arbitrage opportunities in two ways. First, we count the number of limit orders that lead to arbitrage opportunities (discrepant limit order flow, DLOF) as well as the total number of limit orders (limit order flow, LOF) in each market sequence. Thus, the ratio DLOF/LOF measures the proportion of limit orders that generate arbitrage opportunities (Charness and Neugebauer 2019). As second measure we compute the size of the (potential) arbitrage gains in real time, $\pi$. When the arbitrage algorithm is (not) present, the arbitrage values equal the (potential) gains of the arbitrageur.

$$
\pi_{t}=\sum_{\tau} \max \left(0, b_{L, \tau}-o_{U, \tau}+\Delta F V_{t}\right)+\max \left(0, b_{U, \tau}-o_{L, \tau}-\Delta F V_{t}\right),
$$

where $\tau$ denotes time within period $\mathrm{t}, b_{,, \tau}$ and $o_{\cdot, \tau}$ denote the best outstanding limit order bid and offer at time $\tau$ in the L-share and the U-share, respectively. 
We measure the deviations from fundamental dividend values in two ways. First, we measure the expected excess return of buying and selling off the fundamental dividend value including the expected liquidation payment at the end of market sequence $(\mathrm{j}=1,2$ indicates L-share and $\mathrm{U}$-share, $\mathrm{J}=2)$ :

$$
D F_{j, t}=\frac{S_{j, t}}{F V_{j, t}}-1 ;
$$

$\mathrm{DF}$ is the relative deviation from fundamentals and $\mathrm{ADF}$ is the absolute relative deviation from fundamentals over the course of the market sequence:

$$
\begin{array}{lrl}
D F_{t}=\frac{1}{J} \sum_{j=1}^{J} D F_{j, t} ; & D F=\frac{1}{T} \sum_{t=1}^{T} D F_{t} \\
A D F_{t}=\frac{1}{J} \sum_{j=1}^{J}\left|D F_{j, t}\right| ; & A D F=\frac{1}{T} \sum_{t=1}^{T} A D F_{t}
\end{array}
$$

$\mathrm{ADF}$ can be compared to ADPP. If ADF exceeds ADPP then we have that the price trajectories converge on parity rather than on fundamental payout values, and vice versa. As second set of measure we use the relative deviation, $\mathrm{RD}$, and the relative absolute deviation, RAD, which has been applied as mispricing measure visà-vis fundamentals in single-asset market experiments (e.g., Stöckl, Huber, Kirchler 2010).

$$
\begin{gathered}
R D_{j}=\frac{1}{T F V_{j}} \sum_{t=1}^{T} S_{j, t}-F V_{j, t} \\
R A D_{j}=\frac{1}{T F V_{j}} \sum_{t=1}^{T}\left|S_{j, t}-F V_{j, t}\right|
\end{gathered}
$$

Since L-share and U-share trade at the same time, we define the average of the individual asset measures as the relative deviation $R D=0.5\left(R D_{L}+R D_{U}\right)$ and relative absolute deviation, $R A D=0.5\left(R A D_{L}+R A D_{U}\right)$.

\subsection{Testable research questions}

The Modigliani-Miller theorem implies the following testable hypotheses: $\mathrm{DPP}=0$, $\mathrm{ADPP}=0, \pi=0$. In fact, it would also be sufficient for the confirmation of the MM theorem, if asset prices would always confirm fundamentals, that is, $A D F=0$ and $R A D_{L}=0=R A D_{U}$. The test of the MM theorem in our experimental environment is our main research question. More detailed testable research questions follow: 
1. Are relative prices in equilibrium when dividends are identical?

2. Are relative prices in equilibrium when dividends are different?

3. Does our algorithmic arbitrageur help to establish the law of one price when dividends are different or identical?

4. Do we observe mispricing vis-a-vis the fundamental value? Does it get worse when dividends are different rather than when they are identical?

5. Does mispricing seize with experience of subjects?

6. Does our algorithmic arbitrageur help to eliminate mispricing?

7. Does our algorithmic arbitrageur affect market liquidity, volume and volatility?

8. Does our algorithmic arbitrageur impact a price movement towards fundamentals?

\section{Results}

The data of one cohort represent one independent observation, such that we have 32 independent observations in total. Overall, 256 subjects participated in the study, of which 47 percent were female. On average, subjects stated risk aversion on a 7-point Likert scale was 3.59 (indicating risk neutrality). An overview of our data preliminaries is presented by Table 2. We have organized this section in three subsections. In each subsection we present our observations including the supportive data analysis.

\subsection{Law of one price}

Our first test of the Modigliani-Miller theorem of the law of one price is based on the deviations from parity pricing, DPP (Equation 4). The measured average deviations from parity are reported in Table 3, organized chronologically by market and treatment. The test results are indicated.

ObSERVATION I (PARITy PRICING): Parity pricing cannot be rejected in three out of four treatments. Only in the TwoUrn/NoBot treatment with no participation of the algorithmic arbitrageur, the law of one price must be rejected. 
Table 2: Descriptive statistics Average values of relative deviations from price parity, DPP, absolute deviations from price parity, ADPP, relative deviations from fundamental values, DF, absolute deviations from fundamental values, ADF, (potential) arbitrage gains, $\pi$, and average-subject characteristics stated in the questionnaire, organized by treatment condition. (Standard deviations are reported in parentheses).

\begin{tabular}{lccccc}
\hline & \multicolumn{2}{c}{ OneUrn } & & \multicolumn{2}{c}{ TwoUrn } \\
\cline { 2 - 3 } \cline { 5 - 6 } Dot $(n=8)$ & NoBot $(n=8)$ & & Bot $(n=8)$ & NoBot $(n=8)$ \\
\hline \multirow{2}{*}{ DPP } & 0.015 & 0.112 & & -0.013 & -0.037 \\
& $(0.165)$ & $(0.375)$ & & $(0.168)$ & $(0.197)$ \\
& 0.123 & 0.204 & & 0.128 & 0.149 \\
DF & $(0.081)$ & $(0.220)$ & & $(0.079)$ & $(0.083)$ \\
& -0.130 & -0.027 & & -0.105 & 0.002 \\
ADF & $(0.159)$ & $(0.239)$ & & $(0.230)$ & $(0.174)$ \\
& 0.223 & 0.242 & & 0.250 & 0.202 \\
$\pi$ & $(0.096)$ & $(0.139)$ & & $(0.131)$ & $(0.108)$ \\
& 125 & 362 & & 135 & 364 \\
Average CRT score & $(198)$ & $(844)$ & & $(211)$ & $(554)$ \\
& $1.16^{a}$ & $0.75^{a}$ & & 0.875 & 0.656 \\
Average risk seeking & $(0.420)^{a}$ & $(0.199)^{a}$ & & $(0.381)$ & $(0.353)$ \\
& 3.31 & 3.75 & & 3.64 & 3.67 \\
Average female ratio & $(0.456)$ & $(0.678)$ & & $(0.572)$ & $(0.623)$ \\
& 0.453 & 0.453 & & 0.531 & 0.438 \\
& $(0.234)$ & $(0.107)$ & $(0.241)$ & $(0.166)$ \\
\hline \hline
\end{tabular}

${ }^{a}$ These values are based on 4 instead of 8 cohorts. 
Table 3: Deviations from parity pricing - descriptive statistics. Average relative deviation from parity pricing, DPP, by market and treatment condition in columns (1)-(2), and (4)-(5). Columns (3) and (6) report p-values for WilcoxonMann-Whitney tests; (z-statistics for one-sample and two-sample tests are reported in parentheses).

\begin{tabular}{l|ccc|ccc}
\hline \multirow{4}{*}{ Run } & \multicolumn{5}{|c}{ OneUrn } & \multicolumn{4}{c}{ TwoUrn } \\
& Bot & NoBot & Bot vs. NoBot & Bot & NoBot & Bot vs. NoBot \\
& $(1)$ & $(2)$ & $(3)$ & $(4)$ & $(5)$ & $(6)$ \\
\hline \multirow{3}{*}{ Market 1 } & -0.01 & 0.12 & 0.74 & -0.04 & $-0.06^{* *}$ & 0.46 \\
& $(-0.69)$ & $(-0.17)$ & $(-0.33)$ & $(-1.35)$ & $(-2.17)$ & $(0.73)$ \\
Market 2 & 0.02 & 0.14 & 0.48 & -0.02 & -0.06 & 0.76 \\
& $(0.36)$ & $(1.48)$ & $(-0.71)$ & $(-1.09)$ & $(-1.39)$ & $(0.31)$ \\
Market 3 & 0.04 & 0.11 & 0.77 & -0.03 & $-0.07^{* * *}$ & 0.14 \\
& $(1.02)$ & $(1.31)$ & $(-0.30)$ & $(-0.81)$ & $(-2.71)$ & $(1.47)$ \\
Market 4 & 0.01 & 0.08 & 0.28 & 0.01 & 0.01 & 0.58 \\
& $(0.77)$ & $(1.75)$ & $(-1.09)$ & $(-0.37)$ & $(0.48)$ & $(-0.55)$ \\
Market 5 & 0.02 & $0.12^{* * *}$ & $0.06^{*}$ & -0.03 & $-0.05^{* *}$ & 0.34 \\
& $(1.23)$ & $(3.26)$ & $(-1.89)$ & $(-1.31)$ & $(-1.98)$ & $(0.96)$ \\
Market 6 6 & 0.00 & $0.10^{* * *}$ & $0.07^{*}$ & 0.04 & 0.02 & 0.83 \\
& $(0.33)$ & $(2.63)$ & $(-1.82)$ & $(0.89)$ & $(0.57)$ & $(0.21)$ \\
\hline Average & 0.02 & 0.11 & 0.39 & -0.01 & $-0.04^{* *}$ & 0.39 \\
& $(0.00)$ & $(0.00)$ & $(0.86)$ & $(-1.00)$ & $(-2.00)$ & $(0.86)$ \\
\hline \hline
\end{tabular}

SuPPoRT: Table 3 reports average relative deviations from parity pricing, DPP, by Market, sequence 1 to 6 , for all treatments. Values for DPP are derived as formulated in Equation 3. The average results are shown in the bottom line of the table, see also Table 2. Table 3 indicates that average pricing in the TwoUrn/NoBot treatment, see column (5) of the table, differs from parity significantly. As indicated in the table, some deviations from parity pricing are also indicated in some markets of the OneUrn/NoBot treatment without algorithmic arbitrageur participation. We find no significant deviation from parity pricing in any market where the algorithmic arbitrageur participates.

Observation 1 adds to the supportive evidence of the Modigliani-Miller theorem, but also shows its limitations. Charness and Neugebauer (2019) found that the differences from parity pricing are not significantly different from zero, when dividends are equal modulo a shift. It seems that we have been able to reproduce this effect in the OneUrn treatment condition, where dividend streams for L-shares and U-shares 
Figure 2: Average relative deviation from parity pricing (DPP) by treatment

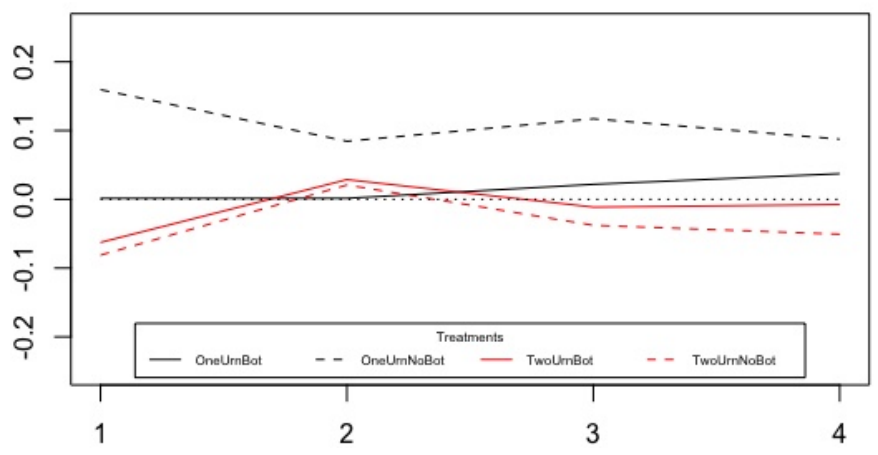

are identical and the differences in the liquidation payments are constant. This result is perhaps not so surprising. For the TwoUrn treatment condition, where dividend streams for L-shares and U-shares are independent, differences from parity pricing are significant on average, unless the algorithmic arbitrageur is present. So what does that tell us about the claim of Miller and Modigliani (1961) that the market value of the firm is independent of its payout policy? Apparently, the Modigliani-Miller law of one price is impacted by differences in the payout policy. This observation, maybe for different reasons or not, underlines the empirical evidence on the relevance of dividend payout policy (DeAngelo and DeAngelo 2006, Asparouhova et al. 2016). To support the law of one price with different dividends, we need an algorithmic arbitrageur in the market. In the TwoUrn/Bot treatment, differences from parity are not significant. The impact of the algorithm on parity pricing is also shown in Figure 2 by period, aggregated over all six markets.

Figure 2 shows the differences from parity pricing, $D P P_{t}$, by period and treatment. (See also Figure 5 in the appendix where the average differences from parity are shown for each dividend pattern of the L-share). The Figure shows that markets in the OneUrn treatment condition, i.e., with identical dividend streams for L-shares and U-shares, appear to reach parity pricing ( $\mathrm{y}=0$, dotted line) when the algorithmic arbitrageur is present (solid black line) but deviate from parity pricing where no algorithm is present (dashed black line). Similarly in the TwoUrn treatment condition, the average prices are closer to parity pricing in the presence of the algorithm. In the NoBot treatment condition (dashed red line), prices are further away from parity pricing than in the Bot markets (solid red line). We now turn to a more demanding test of the Modigliani-Miller law of one price, via the absolute deviations from parity pricing, ADPP. 
Table 4: Deviations from parity pricing - regression results. Results from OLS regressions with robust standard errors. Average relative deviation from price parity, $D P P$, and average absolute deviation from price parity, $A D P P$, are derived as defined in Equations 4 and 5 . Bot and TwoUrn are treatment dummies. Market indicates the market sequence, ranging from 1 to 6 . avRisk is the average selfreported willingness to take risks on a 7-point Likert scale for each cohort. avFemale is the proportion of female participants within a respective cohort. avCRT is the average score in a standard CRT test for each cohort, CRT-scores range from 0 to 3 according to the number of correct answers. The mean has been subtracted from the last three measures to allow for a more meaningful interpretation of the intercept.

\begin{tabular}{|c|c|c|c|c|c|c|}
\hline & \multicolumn{6}{|c|}{ Dependent variable: } \\
\hline & \multicolumn{3}{|c|}{$\mathrm{DPP}$} & \multicolumn{3}{|c|}{$\mathrm{ADPP}$} \\
\hline & $(1)$ & $(2)$ & $(3)$ & $(4)$ & $(5)$ & $(6)$ \\
\hline \multirow[t]{2}{*}{ Constant } & 0.068 & -0.021 & -0.104 & $0.254^{* * *}$ & $0.160^{* * *}$ & $0.233^{* * *}$ \\
\hline & $(0.049)$ & $(0.055)$ & $(0.068)$ & $(0.038)$ & $(0.044)$ & $(0.042)$ \\
\hline \multirow[t]{2}{*}{ Bot } & -0.039 & -0.026 & 0.022 & $-0.052^{* * *}$ & $-0.055^{* * *}$ & 0.021 \\
\hline & $(0.024)$ & $(0.023)$ & $(0.021)$ & $(0.019)$ & $(0.018)$ & $(0.014)$ \\
\hline \multirow[t]{2}{*}{ TwoUrn } & $-0.089^{* * *}$ & $-0.090^{* * *}$ & -0.016 & -0.025 & -0.030 & 0.0005 \\
\hline & $(0.024)$ & $(0.025)$ & $(0.019)$ & $(0.019)$ & $(0.019)$ & $(0.012)$ \\
\hline \multirow[t]{2}{*}{ Market } & 0.005 & 0.005 & 0.008 & $-0.019^{* * *}$ & $-0.019^{* * *}$ & $-0.012^{* * *}$ \\
\hline & $(0.007)$ & $(0.007)$ & $(0.005)$ & $(0.006)$ & $(0.006)$ & $(0.004)$ \\
\hline \multirow[t]{2}{*}{ avRisk } & & $0.037^{* *}$ & $0.033^{* *}$ & & 0.012 & 0.014 \\
\hline & & $(0.016)$ & $(0.016)$ & & $(0.013)$ & $(0.011)$ \\
\hline \multirow[t]{2}{*}{ avFemale } & & $-0.109^{* * *}$ & $-0.154^{* *}$ & & $0.121^{* * *}$ & -0.060 \\
\hline & & $(0.039)$ & $(0.063)$ & & $(0.027)$ & $(0.040)$ \\
\hline \multirow[t]{2}{*}{ avCRT } & & & 0.016 & & & $-0.109^{* * *}$ \\
\hline & & & $(0.035)$ & & & $(0.024)$ \\
\hline Observations & 192 & 192 & 144 & 192 & 192 & 144 \\
\hline $\mathrm{R}^{2}$ & 0.081 & 0.103 & 0.141 & 0.102 & 0.141 & 0.251 \\
\hline Adjusted $\mathrm{R}^{2}$ & 0.066 & 0.079 & 0.103 & 0.088 & 0.117 & 0.218 \\
\hline F Statistic & $5.488^{* * *}$ & $4.279^{* * *}$ & $3.751^{* * *}$ & $7.109^{* * *}$ & $6.085^{* * *}$ & $7.649^{* * *}$ \\
\hline
\end{tabular}

Observation II (Absolute Deviation from Parity Pricing): ADPP measures are significantly positive for all markets and treatment conditions. ADPP measures are significantly smaller in the presence of the algorithmic arbitrageur, and diminish with experience. 
SupPORT: Table 2 records average ADPP measures by treatment sequence, ranging from 0.123 to 0.204 . Table 4 reports regression results with and without control variables. We estimate the impact of our treatment conditions using OLS regression with robust standard errors, clustered at cohort level. The regressions show that ADPP is significantly smaller when the algorithmic arbitrageur is present than when it is not. The regression results further show that the pricing discrepancies get smaller with repetition, indicated by Market. Table 4 also suggest that absolute deviation from parity pricing are smaller in cohorts with higher average CRT-scores.

Observation III (Potential Arbitrage Gains): The (potential) arbitrage gains are smaller when the algorithmic arbitrageur is present. Repetition and market acuity leads to a reduction in discrepant orders.

SupporT: Table 2 shows the (potential) gains from arbitrage $\pi$ per market for each treatment. The regression results in Table 5 show that the potential arbitrage gains are significantly smaller in treatments with algorithmic arbitrageur than without. The main reason is probably that discrepant limit orders remain outstanding in the market for longer and thus trigger more discrepant limit orders subsequently through competition. Interestingly, the (potential) arbitrage gains seem independent of the treatment condition; it only matters if an arbitrageur is present or not. The regression in Table 5 shows that the repetition, Market, and the CRT-score of the market have a negative impact on (potential) arbitrage gains. The regression results of the number of discrepant limit orders do not suggest that the relative frequency of discrepant limit orders diminishes. Apparently, arbitrage opportunities diminish in size but not its relative frequency.

\subsection{Expected dividend value}

We are also interested in the determinants of market prices, in particular, in the impact of the algorithmic arbitrageur on asset prices relative to fundamentals. The traditional view on Wall Street is that the activity of well-paid professions who engage in arbitrage pushes prices towards fundamentals. As described in section 3, we have different measures of mispricing vis-à-vis fundamentals; DF, ADF, RD and RAD.

Observation IV (Deviation from fundamentals) The presence of the algorithmic arbitrageur does not facilitate convergence of market prices towards fun- 
Table 5: Arbitrage opportunities. Results from OLS regressions with robust standard errors. The cumulative value of potential arbitrage gains $\pi$ per market sequence and the proportion of discrepant limit orders $(D L O F)$ of total limit orders $(L O F)$ in percent are measured as defined in Equation 6. Bot and TwoUrn are treatment dummies. Market indicates the market sequence, ranging from 1 to 6 . avRisk is the average self-reported willingness to take risks on a 7-point Likert scale for each cohort. avFemale is the proportion of female participants within a cohort. avCRT is the average score in a standard CRT test within a cohort. The mean has been subtracted from the last three measures to allow for a more meaningful interpretation of the intercept.

\begin{tabular}{|c|c|c|c|c|c|c|}
\hline & \multicolumn{6}{|c|}{ Dependent variable: } \\
\hline & \multicolumn{3}{|c|}{$\sum \pi_{t}$} & \multicolumn{3}{|c|}{$\mathrm{DLOF} / \mathrm{LOF}$ (in \%) } \\
\hline & $(1)$ & $(2)$ & $(3)$ & $(4)$ & $(5)$ & $(6)$ \\
\hline Constant & $\begin{array}{c}627.748^{* * *} \\
(177.973)\end{array}$ & $\begin{array}{c}660.789^{* * *} \\
(247.986)\end{array}$ & $\begin{array}{l}924.434^{* *} \\
(363.267)\end{array}$ & $\begin{array}{c}4.056^{* * *} \\
(0.705)\end{array}$ & $\begin{array}{l}4.685^{* *} \\
(1.998)\end{array}$ & $\begin{array}{l}5.568^{*} \\
(2.847)\end{array}$ \\
\hline Bot & $\begin{array}{c}-233.177^{* * *} \\
(73.968)\end{array}$ & $\begin{array}{c}-261.482^{* * *} \\
(77.694)\end{array}$ & $\begin{array}{l}-96.071 \\
(60.923)\end{array}$ & $\begin{array}{c}-2.088^{* * *} \\
(0.480)\end{array}$ & $\begin{array}{c}-2.096^{* * *} \\
(0.478)\end{array}$ & $\begin{array}{c}-1.902^{* * *} \\
(0.612)\end{array}$ \\
\hline TwoUrn & $\begin{array}{c}6.281 \\
(73.968)\end{array}$ & $\begin{array}{c}1.603 \\
(78.029)\end{array}$ & $\begin{array}{c}58.100 \\
(55.304)\end{array}$ & $\begin{array}{c}0.732 \\
(0.480)\end{array}$ & $\begin{array}{c}0.761 \\
(0.505)\end{array}$ & $\begin{array}{c}0.802 \\
(0.671)\end{array}$ \\
\hline Market & $\begin{array}{c}-76.563^{* * *} \\
(27.640)\end{array}$ & $\begin{array}{c}-76.563^{* * *} \\
(27.433)\end{array}$ & $\begin{array}{c}-50.545^{* * *} \\
(18.472)\end{array}$ & $\begin{array}{l}-0.193 \\
(0.138)\end{array}$ & $\begin{array}{l}-0.193 \\
(0.138)\end{array}$ & $\begin{array}{l}-0.157 \\
(0.169)\end{array}$ \\
\hline avRisk & & $\begin{array}{l}-50.458 \\
(70.936)\end{array}$ & $\begin{array}{l}-34.406 \\
(65.282)\end{array}$ & & $\begin{array}{l}-0.120 \\
(0.637)\end{array}$ & $\begin{array}{c}0.125 \\
(0.691)\end{array}$ \\
\hline avFemale & & $\begin{array}{l}351.539^{* *} \\
(147.937)\end{array}$ & $\begin{array}{l}-230.079 \\
(232.353)\end{array}$ & & $\begin{array}{l}-0.440 \\
(1.390)\end{array}$ & $\begin{array}{l}-2.807 \\
(2.373)\end{array}$ \\
\hline avCRT & & & $\begin{array}{c}-353.804^{* * *} \\
(133.985) \\
\end{array}$ & & & $\begin{array}{l}-1.174 \\
(1.219) \\
\end{array}$ \\
\hline Observations & 192 & 192 & 144 & 192 & 192 & 144 \\
\hline $\mathrm{R}^{2}$ & 0.107 & 0.122 & 0.200 & 0.110 & 0.111 & 0.133 \\
\hline Adjusted $\mathrm{R}^{2}$ & 0.092 & 0.099 & 0.165 & 0.096 & 0.087 & 0.095 \\
\hline F Statistic & $7.482^{* * *}$ & $5.179^{* * *}$ & $5.708^{* * *}$ & $7.724^{* * *}$ & $4.647^{* * *}$ & $3.497^{* * *}$ \\
\hline
\end{tabular}


Table 6: Deviation from fundamental values Results from OLS regressions with clustered standard errors. Standard errors are reported in parentheses. Absolute and relative deviation from fundamental dividend values per period, $\mathrm{ADF}_{t}$ and $\mathrm{DF}_{t}$, as defined in Equations 8 and 9, Bot and TwoUrn are treatment dummies. Market indicates the market sequence, ranging from 1 to 6 . The cash/asset ratio is defined as the ratio between all available cash and the fundamental value of all outstanding shares. avRisk is the average self-reported willingness to take risks on a 7-point Likert scale for each cohort. avFemale is the proportion of female participants within a cohort. avCRT is the average score in a standard CRT test within a cohort. The mean has been subtracted from the last four measures to allow for a more meaningful interpretation of the intercept.

\begin{tabular}{|c|c|c|c|c|c|c|}
\hline & \multicolumn{6}{|c|}{ Dependent variable: } \\
\hline & $(1)$ & $\begin{array}{c}\mathrm{ADF}_{t} \\
(2) \\
\end{array}$ & $(3)$ & $(4)$ & $\begin{array}{c}\mathrm{DF}_{t} \\
(5) \\
\end{array}$ & $(6)$ \\
\hline Constant & $\begin{array}{c}0.265^{* * *} \\
(0.020)\end{array}$ & $\begin{array}{c}0.303^{* * *} \\
(0.031)\end{array}$ & $\begin{array}{c}0.350^{* * *} \\
(0.046)\end{array}$ & $\begin{array}{l}-0.026 \\
(0.028)\end{array}$ & $\begin{array}{c}-0.265^{* * *} \\
(0.048)\end{array}$ & $\begin{array}{c}-0.372^{* * *} \\
(0.071)\end{array}$ \\
\hline Bot & $\begin{array}{c}0.017 \\
(0.012)\end{array}$ & $\begin{array}{l}-0.003 \\
(0.011)\end{array}$ & $\begin{array}{c}0.025^{*} \\
(0.015)\end{array}$ & $\begin{array}{c}-0.098^{* * *} \\
(0.019)\end{array}$ & $\begin{array}{c}-0.073^{* * *} \\
(0.017)\end{array}$ & $\begin{array}{c}-0.058^{* * *} \\
(0.022)\end{array}$ \\
\hline TwoUrn & $\begin{array}{l}-0.004 \\
(0.012)\end{array}$ & $\begin{array}{l}-0.007 \\
(0.012)\end{array}$ & $\begin{array}{c}-0.014 \\
(0.014)\end{array}$ & $\begin{array}{c}0.027 \\
(0.019)\end{array}$ & $\begin{array}{c}0.026 \\
(0.018)\end{array}$ & $\begin{array}{c}0.094^{* * *} \\
(0.021)\end{array}$ \\
\hline Market & $\begin{array}{c}-0.013^{* * *} \\
(0.004)\end{array}$ & $\begin{array}{c}-0.013^{* * *} \\
(0.003)\end{array}$ & $\begin{array}{c}-0.009^{* *} \\
(0.003)\end{array}$ & $\begin{array}{l}-0.002 \\
(0.006)\end{array}$ & $\begin{array}{l}-0.008 \\
(0.005)\end{array}$ & $\begin{array}{c}0.001 \\
(0.006)\end{array}$ \\
\hline Cash/asset ratio & & $\begin{array}{c}0.027 \\
(0.024)\end{array}$ & $\begin{array}{c}0.057^{*} \\
(0.030)\end{array}$ & & $\begin{array}{c}0.275^{* * *} \\
(0.035)\end{array}$ & $\begin{array}{c}0.242^{* * *} \\
(0.045)\end{array}$ \\
\hline avRisk & & $\begin{array}{c}-0.037^{* * *} \\
(0.009)\end{array}$ & $\begin{array}{c}-0.050^{* * *} \\
(0.010)\end{array}$ & & $\begin{array}{c}0.089^{* * *} \\
(0.015)\end{array}$ & $\begin{array}{c}0.085^{* * *} \\
(0.015)\end{array}$ \\
\hline avFemale & & $\begin{array}{c}0.228^{* * *} \\
(0.025)\end{array}$ & $\begin{array}{c}0.209^{* * *} \\
(0.044)\end{array}$ & & $\begin{array}{c}-0.154^{* * *} \\
(0.039)\end{array}$ & $\begin{array}{c}-0.152^{* *} \\
(0.070)\end{array}$ \\
\hline avCRT & & & $\begin{array}{c}-0.014 \\
(0.027)\end{array}$ & & & $\begin{array}{c}0.020 \\
(0.038)\end{array}$ \\
\hline Observations & 735 & 735 & 549 & 735 & 735 & 549 \\
\hline $\mathrm{R}^{2}$ & 0.019 & 0.094 & 0.140 & 0.040 & 0.165 & 0.169 \\
\hline Adjusted $\mathrm{R}^{2}$ & 0.015 & 0.086 & 0.128 & 0.036 & 0.158 & 0.158 \\
\hline F Statistic & $4.788^{* * *}$ & $12.554^{* * *}$ & $12.535^{* * *}$ & $10.171^{* * *}$ & $23.986^{* * *}$ & $15.739^{* * *}$ \\
\hline
\end{tabular}


Table 7: Measures of market liquidity - regression results. Results from OLS regressions with clustered standard errors. Standard errors are reported in parentheses. $v_{0} l_{t}$ is the total number of shares traded per period. Spread $t_{t}$ is the average percentage spread between the median best ask and median best bid per period. Bot and TwoUrn are treatment dummies. Market indicates the market sequence, ranging from 1 to 6 . The cash/asset ratio is defined as the ratio between all available cash and the fundamental value of all outstanding shares. avRisk is the average self-reported willingness to take risks on a 7-point Likert scale for each cohort. avFemale is the proportion of female participants within a cohort. avCRT is the average score in a standard CRT test within a cohort. The mean has been subtracted from the last four measures to allow for a more meaningful interpretation of the intercept.

\begin{tabular}{|c|c|c|c|c|c|c|}
\hline & \multicolumn{6}{|c|}{ Dependent variable: } \\
\hline & \multicolumn{3}{|c|}{$\mathrm{Vol}_{t}$} & \multicolumn{3}{|c|}{ Spread $_{t}$} \\
\hline & $(1)$ & $(2)$ & (3) & $(4)$ & $(5)$ & $(6)$ \\
\hline Constant & $\begin{array}{c}16.777^{* * *} \\
(1.018)\end{array}$ & $\begin{array}{l}6.389^{* *} \\
(2.922)\end{array}$ & $\begin{array}{c}13.085^{* * *} \\
(3.470)\end{array}$ & $\begin{array}{c}0.470 \\
(1.018)\end{array}$ & $\begin{array}{c}0.436^{* * *} \\
(0.019)\end{array}$ & $\begin{array}{c}0.492^{* * *} \\
(0.029)\end{array}$ \\
\hline Bot & $\begin{array}{c}4.562^{* * *} \\
(0.728)\end{array}$ & $\begin{array}{c}4.815^{* * *} \\
(0.709)\end{array}$ & $\begin{array}{c}7.293^{* * *} \\
(1.276)\end{array}$ & $\begin{array}{l}-0.018 \\
(0.728)\end{array}$ & $\begin{array}{c}-0.020^{* * *} \\
(0.006)\end{array}$ & $\begin{array}{c}0.0002 \\
(0.009)\end{array}$ \\
\hline TwoUrn & $\begin{array}{l}-0.021 \\
(0.728)\end{array}$ & $\begin{array}{c}-0.422 \\
(0.693)\end{array}$ & $\begin{array}{c}-0.816 \\
(0.827)\end{array}$ & $\begin{array}{l}-0.022 \\
(0.728)\end{array}$ & $\begin{array}{c}-0.021^{* * *} \\
(0.006)\end{array}$ & $\begin{array}{c}-0.032^{* * *} \\
(0.008)\end{array}$ \\
\hline Market & $\begin{array}{c}-1.341^{* * *} \\
(0.232)\end{array}$ & $\begin{array}{c}-1.413^{* * *} \\
(0.227)\end{array}$ & $\begin{array}{c}-1.414^{* * *} \\
(0.278)\end{array}$ & $\begin{array}{c}0.004 \\
(0.232)\end{array}$ & $\begin{array}{l}-0.001 \\
(0.002)\end{array}$ & $\begin{array}{r}-0.003 \\
(0.002)\end{array}$ \\
\hline Cash/asset ratio & & $\begin{array}{c}3.507^{* * *} \\
(1.197)\end{array}$ & $\begin{array}{l}3.864^{* *} \\
(1.534)\end{array}$ & & $\begin{array}{c}0.271^{* * *} \\
(0.013)\end{array}$ & $\begin{array}{c}0.279^{* * *} \\
(0.016)\end{array}$ \\
\hline avRisk & & $\begin{array}{c}2.279^{* * *} \\
(0.778)\end{array}$ & $\begin{array}{c}4.662^{* * *} \\
(0.861)\end{array}$ & & $\begin{array}{l}0.011^{* *} \\
(0.005)\end{array}$ & $\begin{array}{c}0.009 \\
(0.006)\end{array}$ \\
\hline avFemale & & $\begin{array}{c}5.387^{* * *} \\
(1.905)\end{array}$ & $\begin{array}{c}-10.249^{* * *} \\
(3.183)\end{array}$ & & $\begin{array}{l}0.033^{*} \\
(0.018)\end{array}$ & $\begin{array}{l}-0.020 \\
(0.028)\end{array}$ \\
\hline avCRT & & & $\begin{array}{c}-11.329^{* * *} \\
(2.045)\end{array}$ & & & $\begin{array}{l}-0.024 \\
(0.016)\end{array}$ \\
\hline Observations & 768 & 768 & 576 & 768 & 768 & 576 \\
\hline $\mathrm{R}^{2}$ & 0.094 & 0.133 & 0.179 & 0.019 & 0.450 & 0.429 \\
\hline Adjusted $\mathrm{R}^{2}$ & 0.090 & 0.127 & 0.169 & 0.015 & 0.445 & 0.422 \\
\hline F Statistic & $26.310^{* * *}$ & $19.528^{* * *}$ & $17.741^{* * *}$ & $4.915^{* * *}$ & $103.621^{* * *}$ & $60.967^{* * *}$ \\
\hline
\end{tabular}


damental values.

SupporT: Table 2 exhibits average measures of DF, ADF, RD and RAD. Noteworthy, the ADF measures are larger than the ADPP measure in every treatment, indicating that prices rather converge on parity than on fundamentals. Table 6 shows regression results with $\mathrm{DF}, \mathrm{ADF}$ and Table 8 in appendix $\mathrm{B}$ shows regression results with RAD and RD as response variables. Table 6 indicates no treatment effect on the ADF measure, see columns (1)-(3). A significant determinant of the ADF measure seems to be repetition; in later market sequences the ADF measure is smaller. The cohort's average risk aversion and its female share seem to have an opposing effect. If the algorithm has an effect on ADF, then it is an increasing effect as suggested in column (3) of Table 6. It seems that the algorithmic arbitrageur in our design rather impacts a lower price level than moving towards fundamentals, see columns (4)-(6). The cohort's average risk aversion and its female share seem to have an opposing effect. Similarly, the cohort's average risk aversion and its female share seem to have a negative price impact, see columns (5)-(6). Table 8 in appendix B confirms these effects for the market sequence level on the basis of RD and RAD measures.

\subsection{Algorithmic trading and market quality}

In this section we summarize and address the effects of the algorithm in our data. In the above observations, we have seen that the algorithmic arbitrageur amends deviations from the law of one price. In particular, we found no market with participation of the algorithm in which the deviations from parity pricing were significant. In sharp contrast we found in absence of the algorithm that in the TwoUrn condition the deviations from the law of one price are significant on average. We have reported that algorithm participation reduces the price discrepancies in size and quantity, both in real time and on period averages. Nonetheless, the absolute price deviations from fundamentals were not impacted. Further impacts on market quality of the algorithmic arbitrageur are described in the following.

Observation V (Trading Volume): The number of limit orders is not negatively impacted and the number of transactions is significantly larger when the algorithm is present.

SupporT: Table 7 exhibits the regression results of the determinants of the number of transactions in our markets. The average number of limit orders per period is 56 when the algorithm is present in the market and 51 when it is not. Hence, 
the presence of the algorithm rather increases than decreases the number of limit orders. As indicated in Table 7, the number of transactions is significantly larger when the algorithmic arbitrager is present, i.e., by about two units per period. Finally, repetition has a negative impact on the number of transactions in our markets.

Observation VI (CAsh/Asset Ratio) Price level and transaction volume positively correlate with the cash amount in the market.

SupporT: Table 6 shows the price relative to fundamentals, and Table 7 shows the number of transactions. In both regressions we report the cash/asset ratio as explanatory variable. The cash/asset ratio is significant in these regressions. The higher price level suggests that after a positive dividend payment, when we have a higher cash/asset ratio and a decrease in fundamental value, prices are high relative to fundamentals, and vice versa. This effect can be impacted by price inertia, i.e., when investors' price adjustments are too conservative re fundamentals.

\section{Conclusion}

We have reported experimental data on the question whether the Modigliani-Miller law of one price is impacted by differences in dividend payouts. On the basis of our data analysis the following conclusions seem to be justified. We have weakly positive support for the law of one price, but find important limitations.

The average prices of our leveraged and unleveraged assets are not significantly different from another when dividends are identical. When dividends are identical, we cannot reject parity pricing on the overall data. However, when dividends are independent, parity pricing can be supported only if an algorithm exploits the arbitrage opportunities in the market and thus pushes prices to parity. This result is quite interesting. It suggests that when the differences in fundamental values get cognitively more demanding, then the law of one price can break down. It also suggests that an arbitrageur in the market can help to support the law of one price. That result appears to us also interesting, because it explains what kind of market forces are required at a minimum to support this important theoretical result of Miller and Modigliani (1961) on the irrelevance of dividend policy for market valuation. 


\section{References}

Abbink, K. and Rockenbach, B. (2006). Option pricing by students and professional traders: a behavioural investigation. Managerial and Decision Economics, $27(6): 497-510$.

Aldrich, E. M. and Vargas, K. L. (2019). Experiments in high-frequency trading: comparing two market institutions. Experimental Economics, pages 1-31.

Asparouhova, E., Besliu, C., Lemmon, M., and Rock, B. (2016). Payout policy, investor rationality, and market efficiency: Evidence from laboratory experiments. Technical report, Working paper, University of Utah.

Bossaerts, P., Shachat, J., and Xie, K. (2018). Arbitrage opportunities: Anatomy and remediation.

Charness, G. and Neugebauer, T. (2019). A test of the modigliani-miller invariance theorem and arbitrage in experimental asset markets. The Journal of Finance, 74(1):493-529.

DeAngelo, H. and DeAngelo, L. (2006). The irrelevance of the mm dividend irrelevance theorem. Journal of Financial Economics, 79(2):293-315.

Durand, D. (1959). The cost of capital, corporation finance, and the theory of investment: comment. The American Economic Review, 49(4):639-655.

Farjam, M. and Kirchkamp, O. (2018). Bubbles in hybrid markets: How expectations about algorithmic trading affect human trading. Journal of Economic Behavior \&f Organization, 146:248-269.

Fischbacher, U. (2007). z-tree: Zurich toolbox for ready-made economic experiments. Experimental economics, 10(2):171-178.

Gode, D. K. and Sunder, S. (1993). Allocative efficiency of markets with zerointelligence traders: Market as a partial substitute for individual rationality. Journal of Political Economy, 101(1):119-137.

Greiner, B. (2015). Subject pool recruitment procedures: organizing experiments with orsee. Journal of the Economic Science Association, 1(1):114-125.

Leal, S. J., Hanaki, N., et al. (2018). Algorithmic trading, what if it is just an illusion? evidence from experimental financial markets. Technical report, Groupe de REcherche en Droit, Economie, Gestion (GREDEG CNRS), University of .... 
Levati, M. V., Qiu, J., and Mahagaonkar, P. (2012). Testing the modigliani-miller theorem directly in the lab. Experimental Economics, 15(4):693-716.

Miller, M. H. (1988). The modigliani-miller propositions after thirty years. Journal of Economic Perspectives, 2(4):99-120.

Miller, M. H. and Modigliani, F. (1961). Dividend policy, growth, and the valuation of shares. Journal of Business, 34(4):411-433.

Modigliani, F. and Miller, M. H. (1958). The cost of capital, corporation finance and the theory of investment. The American Economic Review, 48(3):261-297.

Modigliani, F. and Miller, M. H. (1959). The cost of capital, corporation finance, and the theory of investment: Reply. The American Economic Review, 49(4):655-669.

O'brien, J. and Srivastava, S. (1991). Dynamic stock markets with multiple assets: An experimental analysis. The Journal of Finance, 46(5):1811-1838.

Stöckl, T., Huber, J., and Kirchler, M. (2010). Bubble measures in experimental asset markets. Experimental Economics, 13(3):284-298. 


\section{Appendix}

\section{A Instructions}

Welcome and thank you for participating in our experiment on decision-making in asset markets. If you read these instructions carefully and make good decisions, you might earn a considerable amount of money. This money will be paid to you in cash after the session. Do not use hand phones, laptop computers, or use the lab's desktop computer except for the experimental software application. Please refrain from talking for the duration of the experiment, or looking at others' computer monitors. If at some point you have a question, please raise your hand and we will address it as soon as possible. You must observe these rules, otherwise we will have to exclude you from this experiment and all associated payments, and ask you to leave.

\section{A.1 Shares, cash, and earnings}

In this experiment, you will participate in a market of 8 participants. The identities of the other market participants will not be revealed to you. You will interact with the same participants in 6 successive rounds of 4 periods.

At the beginning of each round we give each participant the following: 4000 units of cash, 5 "A"-type shares, and 5 "B"-type shares. Every single share generates a cash payment at the end of each trading period. This payment is called "dividend". A dividend will be +50 or -50 cash units. When dividends are paid on shares you hold the amount is added to, or subtracted, from your cash balance. After 4 dividends are paid, at the end of the round shareholders receive a liquidation payment on all shares, and shares are cancelled thereafter. Liquidation payments are added to a shareholder's cash balance.

You will end each round with a final cash balance. The final cash balance is the basis for your final earnings in this experiment. The timeline of the round is shown in Figure 3 .

Participants in the One Urn Treatment Condition read:

How dividends are determined:

We announce and pay dividends at the conclusion of each period. The A and B share dividends are always equal.

Within a round, for exactly two periods the dividend will be +50 , and for exactly 


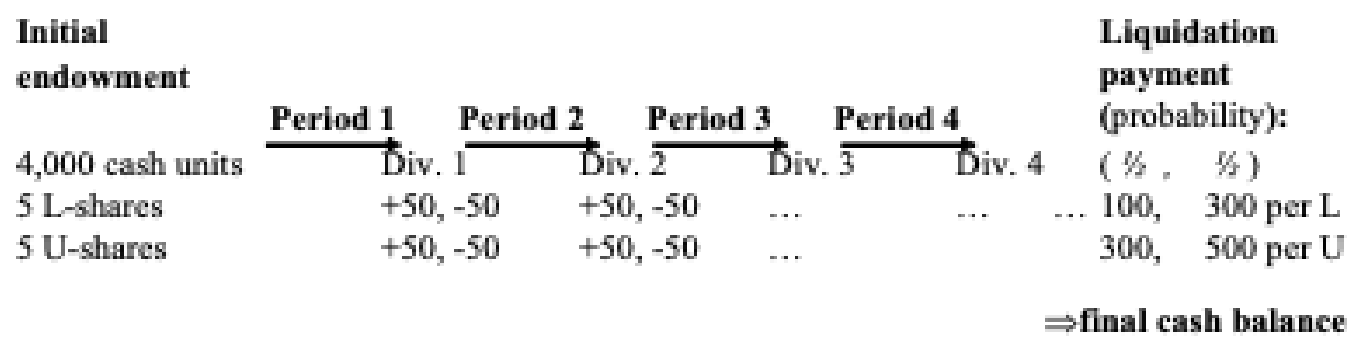

Figure 3: Timeline of the round

two periods the dividend will be -50 cash units. However, the order of the four dividends is random.

The dividend process can be thought of as follows. There is an opaque urn containing two balls marked with the symbol "+", representing +50 dividends each, and two balls marked with the symbol "-", -50 dividends. After the first trading period one of the balls is randomly selected to determine the period one dividend. This ball is discarded, not returned to the urn. This selection is repeated for the next three periods until all of the balls have been selected after trading period four and no balls are left in the urn.

Participants in the Two Urn Treatment Condition read:

How dividends are determined:

We announce and pay dividends at the conclusion of each period. The A and B share dividends may differ or be equal for a given period.

For a given share type and within a round, for exactly two periods the dividend will be +50 , and for exactly two periods the dividend will be -50 cash units. However, the order of the four dividends is random. The order of the A share dividends and the order of the B share dividends are also independent.

The dividend process can be thought of as follows. There are two opaque urns, one for A shares and the other for B shares. The two urns both contain two balls labelled with a "+", representing +50 dividends, and balls labelled with a "-", -50 dividends each. After the first trading period one of the balls is randomly selected from the A share urn to determine the A share dividend of period 1. This ball is discarded, not returned to the urn. We do the same with the other urn, randomly select a ball from the B share urn to determine the B share dividend of that period. These selections are repeated for the next three periods until all of the balls have been selected from both urns after trading period 4 and no balls are left in the urns. - 
How liquidation payments are determined:

The liquidation payment is random. The liquidation payment per A share will be either 100 or 300 cash units; each having an equal chance of selection. The liquidation payment per B share will be exactly 200 cash units more than the one per A share. When the liquidation payment of the A share is 100, then the liquidation payment of the B share will be 300 cash units. Likewise, when the liquidation payment of the A share is 300 , the liquidation payment of the B share will be 500 cash units.

We have used separate coin tosses to determine the liquidation payments for the six rounds before the session. Also prior to the session, we have pre-drawn the dividend series for all trading periods. We have recorded these dividend and liquidation outcomes on paper and placed them in an envelope taped on the wall of the room. At the end of the experiment, we will open the relevant envelopes and project the recorded values for all to see they match those in the experiment. Note that any actions taken in the experiment can not influence these values.

\section{A.2 How to trade shares?}

The experiment is divided into six rounds of 4 consecutive trading Periods. Each trading period in the first two rounds will last 180 seconds, and 120 seconds in the later rounds. In each trading period, you will participate in a market where the Shares can be bought and sold between participants. You pay out of your Cash when you buy a share, and you get Cash when you sell a share. When a period is over, your Cash and Shares will carry over to the next period until the round ends.

We are interested in the price you are bidding to pay and the price you are asking to sell. In order to buy shares, you need cash. If you run out of Cash, you can borrow cash (with no interest) up to 3000 cash units. The cash you own is shown on the screen. If you borrow Cash, your Cash holdings will be negative. In order to sell shares, you need shares. The number of shares you own is indicated at the top of your screen for "A" shares and "B" shares, respectively. If you do not own (enough) shares and wish to sell (more) shares, you can borrow to sell up to 5 "A" shares AND up to 5 "B" shares. If you sell more shares than you own your share holdings will be negative. For a given negative share count at the end of the period, the dividend on these negative shares will be subtracted from your cash, i.e., positive dividends will be subtracted and negative dividends will be added. At the end of the round, the liquidation payment for a given negative share count will be subtracted from your cash balance.

During a period, you may buy or sell shares (see Figure 2 on the next page, and at the end of the Instructions). You can also choose not to trade any shares and 
simply wait and collect dividends. Note that you can only buy or sell one share at a time.

1. Submit an ASK: An ask is a proposed selling price for one share. You offer a share from your share holdings for sale by entering the asking price to sell one share in the space underneath the button ASK: proposed selling price (see Figure 4). You confirm the ask by a click on the button. The ask is then added to the list of outstanding asks. The outstanding asks are publicly recorded in increasing order, i.e. the best outstanding ask (the cheapest proposed selling price) being placed at the top of the list. All market participants can see this list.

Note: you can submit as many asks as you like to sell one share. Upon selling one share, all your outstanding asks (for that share class) are cancelled. To sell another share of that share class, you then must submit a new ask.

2. Submit a BID: A bid is a proposed buying price for one share. You bid to purchase a share by entering your bidding price for one share in the space underneath the button BID: proposed buying price. You confirm your bid by a click on the button. The bid is then added to the list of outstanding bids. The outstanding bids are publicly recorded in decreasing order, i.e., the best outstanding bid (highest proposed purchase price) being placed at the top of the list. All market participants can see this list.

Note: If two or more orders (bids or asks) are the same, they are listed in the order of arrival, earlier orders being given priority over later ones. Upon purchasing one share, all your outstanding bids (for that share class) are cancelled. To buy another share for this share class you then must submit a new bid.

3. Immediate BUY - accept an ask: The best outstanding ask of the other market participants is marked on your screen. You can accept the asking price (i.e., entering in a purchase agreement of a share with the seller) by clicking the button Immediate BUY, which is placed at the bottom of the list of outstanding asks.

4. Immediate SELL - accept a bid: The best outstanding bid of the other market participants is marked. You can accept the bid (i.e., entering in a sale agreement of a share with the buyer) by clicking on the button Immediate SELL, which is placed at the bottom of the list of outstanding bids. 


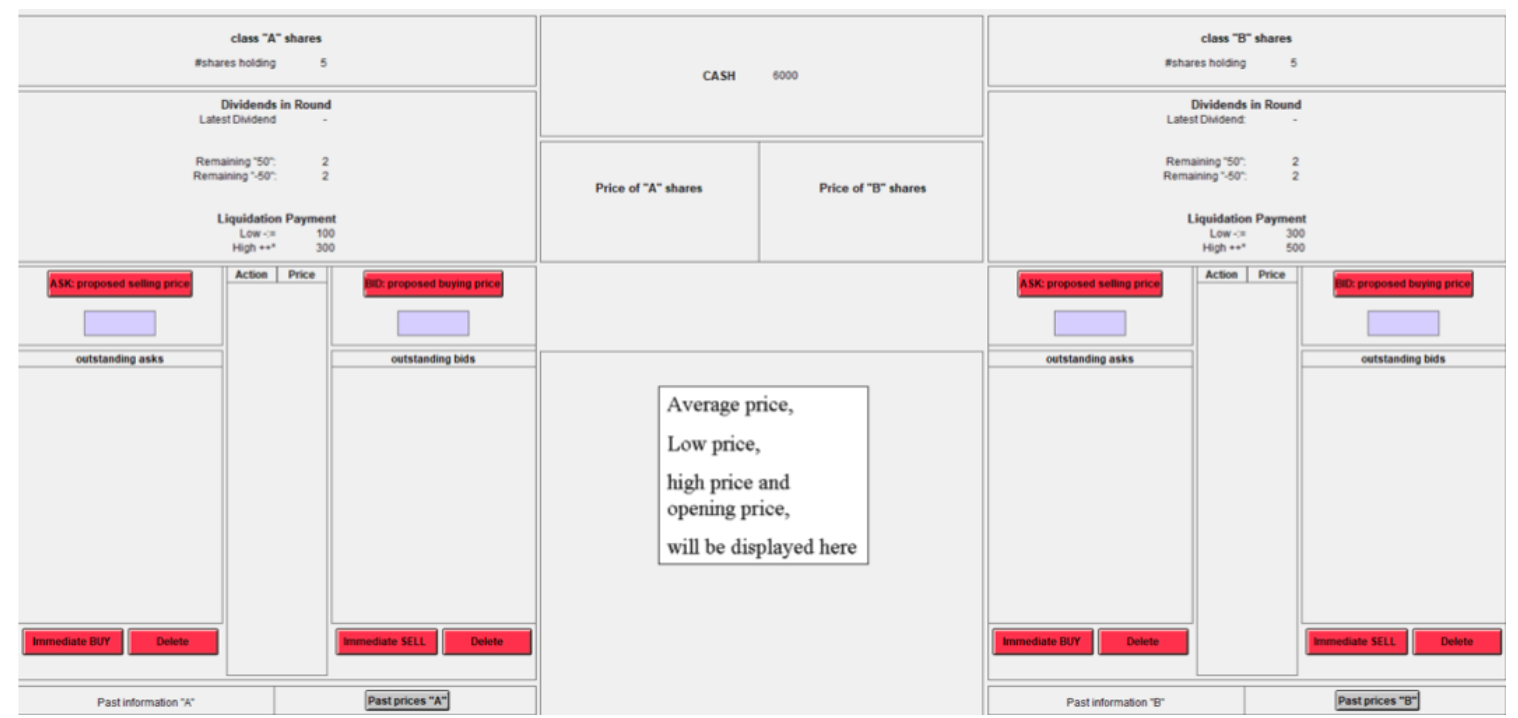

Figure 4: Trading screen

5. Delete - you can delete your outstanding bids and asks. To do so, select your outstanding bid or ask, which are displayed in the list in blue colour and click the button Delete.

Note: Your own orders are displayed in blue, while the other orders are visible to you in black. You cannot accept your own orders. You cannot delete orders of others. You cannot purchase shares if the ask exceeds your cash plus credit line. If your holding of "A" shares is -5, you cannot sell any further "A" shares. If your holding of " $\mathrm{B}$ " shares is -5 , you cannot sell any further "B" shares.

\section{A.3 Transaction and price announcement}

Upon acceptance of a bid or ask, via Immediate BUY or Immediate SELL, a transaction is completed. The accepted order is the transaction price. The transaction price is recorded on your screen in between the lists of bids and asks. Next to the price you are informed if you participated as buyer or seller in the transaction. The more recent prices are listed first. The most recent prices are also recorded for each share class in the middle of the screen below the cash amount.

Upon transacting, the price is debited from the buyer's cash balance and credited to the seller's cash balance. The purchased share is added to the buyer's share holdings and subtracted from the seller's share holding.

Note: Immediately after these instructions, you are going to participate in a Practice Session of trading to familiarize yourself with the trading environment. You trade for 3 minutes on your screen with the other participants. There are NO payoff 
consequences linked to trading in the Practice Session. During the Practice Session please practice submissions of bids and asks, immediate selling and buying, and deleting of your outstanding bids and asks. You may want to practice selling more shares than you own to end up with a negative share count. You may also want to practice buying more shares than you can pay with your own money to end up with a negative cash balance. During the Practice Session none of your actions will have any payoff consequences. The payoff-relevant trading periods begin only after the Practice Session.

\section{A.4 Information}

You will receive real-time updates on bids, asks and prices for both share classes "A" and "B". Information regarding the two share classes are given on the screen on the left-hand and on the right-hand side, respectively. You will receive summary information about the prices at opening of the period, the high, the low and the average price during the period.

In each period, you will be reminded on screen about the remaining future dividends, and the possible liquidation payments at the end of the round. Finally, the realized past dividends are shown. The latest paid out dividend of the prior period is highlighted.

The experimenter recorded the order of the 4 dividends on sheets of paper. Then, the experimenter put the paper into an envelope, which was placed on the wall. At the conclusion of the experiment, the experimenter will show the list of predetermined dividends to confirm they match the dividends observed during the market. You will have a record of your dividend sequence at the final screen. You will be able to compare the dividend sequence on your screen with the predetermined dividends at that time.

The past prices are shown in a table on the bottom of the screen, including the prices at opening, closing, the high, low and average of each past period. Alternatively to the past prices, you receive past information on your share and cash holdings at the end of the period, buys and sells during a period, and the past period

dividends. You can alternate the past information with the past prices by clicking on the button.

\section{A.5 Endowment and earnings}

Your earnings in this experiment will be based on your final cash balances which include Cash holdings as well as liquidation payments for A and B shares at the end 
of a round.

Note: If you have negative Cash holdings after the final period of a round, the amount you borrowed will be subtracted from the total liquidation payment of your shares. If you have negative share holdings, the liquidation payment of the shares you borrowed will be subtracted from your Cash holdings.

The final cash balance of one of the six rounds will be paid out to you at the end of the experiment. The round to be paid out is chosen randomly. The result of this random draw has been determined before the session, and has been recorded on a sheet of paper in the envelope on the wall, which will be revealed to you after the final round. You will also be informed about the decisive round on the screen to confirm that the two numbers match.

At the end of the experiment, cash units (CU) will be converted to Euro, at an exchange rate of $1=300 \mathrm{CU}$. Your final payment will be equal to your final cash balance at the end of the decisive round plus a 5 payment for your participation. The final payment will be made to you in private; you will receive an envelope delivered to your seat in exchange for your signed receipt.

\section{A.6 Trading algorithm}

Besides the participants in the room, a computerized trading algorithm may participate in the market. The computerized algorithm can take the same actions as you, that is, it can buy and sell in the market. The details of the strategy followed by the algorithm are not revealed to you, and you will not be informed whether the computerized trading algorithm actually acts in the market or not.

\section{A.7 Summary}

1. You will be given an initial 4000 units of cash, 5 "A" shares, and 5 "B" shares at the beginning of each round. Over the course of a round, each A-share and each "B" share pays the owner a dividend of either +50 , or -50 . Exactly two dividend payments of each share are positive $(+50)$ and two dividends are negative $(-50)$.

2. At the end of the round, each share pays a liquidation payment. The liquidation payment per A-share is either 100 (if the flip of the coin is heads) or 300 cash units (if the flip of the coin is tails). The liquidation payment per B share is 200 cash units more; that is: 300 (if the flip of the coin is heads) or 500 cash units (if the flip of the coin is tails). 
3. In each period the market will be open for trading, 180 seconds in the first two rounds and 120 seconds in later rounds. You can submit offers to BUY shares and offers to SELL shares. You can make immediate transactions by buying at the lowest ask (offer to sell) or selling at the highest bid (offer to buy). You can delete your offers while outstanding.

4. You will participate in 6 rounds of 4 periods. At the end of the experiment, one round of four periods is selected for payment. The decisive round is determined randomly and is recorded on a sheet of paper in an envelope on taped to the wall, which will be revealed to you after the final round. The decisive round is the same for all participants in a market of eight.

5. Note that if you borrow cash or shares you may end a round with a negative cash balance. If a round is chosen for payment in which you incur losses, you will earn nothing.

6. A computerized trading algorithm may participate in the market. However, you will never be told whether the algorithm acts in the market and, if it does, what it is programmed to do.

7. The instructions are over. If you have any question, raise your hand and consult the monitor. Otherwise, please wait for the following Practice Session of three minutes. 
B Additional figures and tables 
Figure 5: $\mathrm{DPP}_{t}$ by L sequence
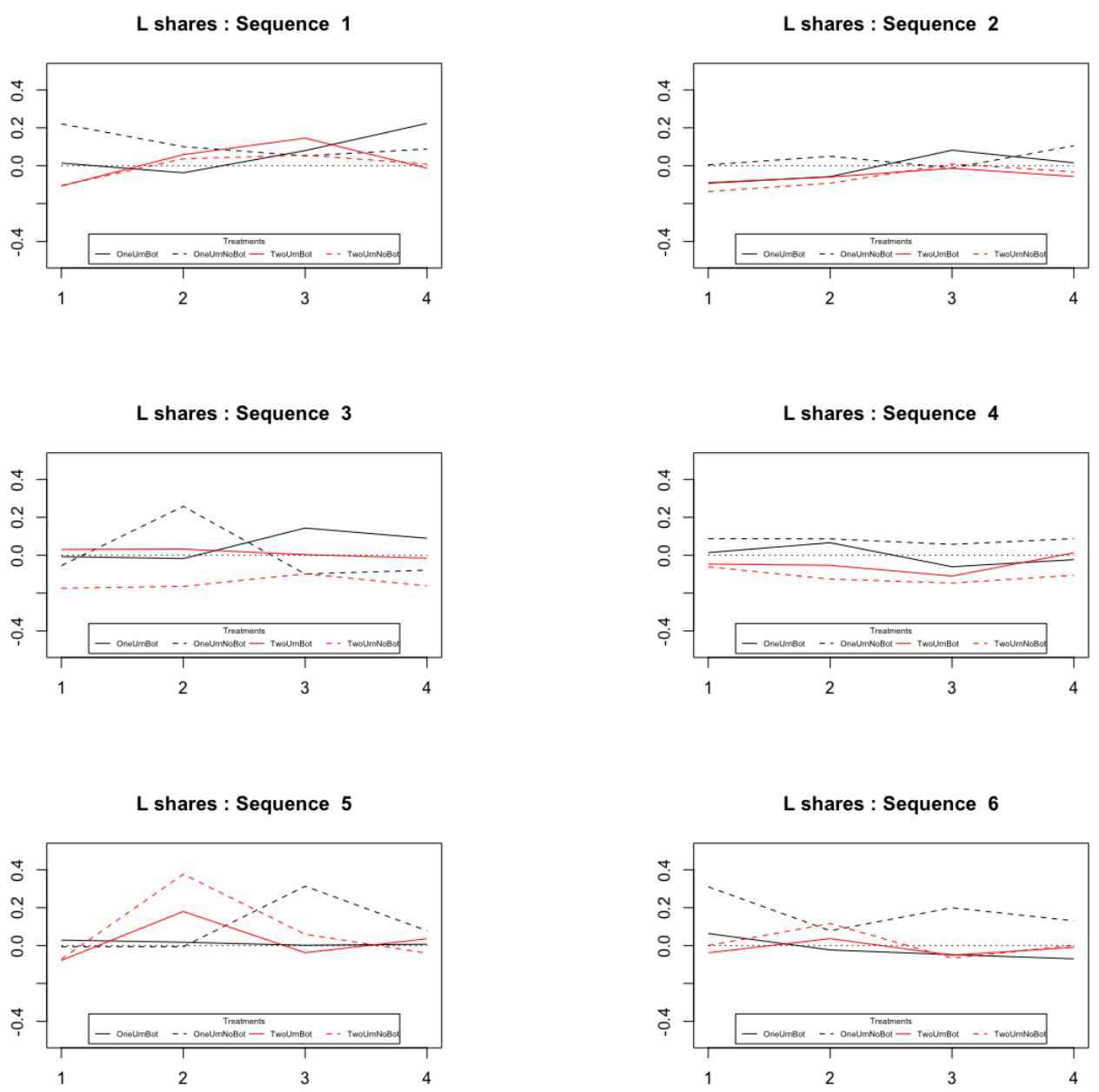

The different sequences of dividends were as follows. Sequence 1: $-50,-50,50,50$, Sequence 2: -50,50,-50,50, Sequence 3: -50,50,50,-50, Sequence 4: 50,-50,-50,50, Sequence 5: 50,-50,50,-50, Sequence 6: 50,50,-50,-50. The dotted line "0" indicates parity pricing. 
Table 8: Relative and absolute mispricing. OLS regressions for relative and relative absolute period-level deviations from fundamental values with robust standard errors. $\mathrm{RAD}_{U, L, t}$ and $\mathrm{RD}_{U, L, t}$ are averages of values for L-shares and U-shares.

\begin{tabular}{|c|c|c|c|c|c|c|}
\hline & \multicolumn{6}{|c|}{ Dependent variable: } \\
\hline & \multicolumn{3}{|c|}{$\operatorname{RAD}_{U, L, t}$} & \multicolumn{3}{|c|}{$\mathrm{RD}_{U, L, t}$} \\
\hline & $(1)$ & $(2)$ & $(3)$ & $(4)$ & $(5)$ & $(6)$ \\
\hline \multirow[t]{2}{*}{ Constant } & $0.294^{* * *}$ & $0.298^{* * *}$ & $0.358^{* * *}$ & -0.066 & $-0.228^{* * *}$ & $-0.345^{* * *}$ \\
\hline & $(0.028)$ & $(0.051)$ & $(0.066)$ & $(0.043)$ & $(0.079)$ & $(0.105)$ \\
\hline \multirow[t]{2}{*}{ Bot } & 0.010 & -0.009 & 0.020 & $-0.091^{* * *}$ & $-0.066^{* *}$ & -0.052 \\
\hline & $(0.018)$ & $(0.016)$ & $(0.025)$ & $(0.028)$ & $(0.026)$ & $(0.034)$ \\
\hline \multirow[t]{2}{*}{ TwoUrn } & -0.010 & -0.014 & -0.024 & 0.037 & 0.035 & $0.109^{* * *}$ \\
\hline & $(0.018)$ & $(0.017)$ & $(0.019)$ & $(0.028)$ & $(0.027)$ & $(0.030)$ \\
\hline \multirow[t]{2}{*}{ Market } & $-0.015^{* * *}$ & $-0.015^{* * *}$ & $-0.012^{* *}$ & -0.003 & -0.003 & 0.006 \\
\hline & $(0.006)$ & $(0.005)$ & $(0.006)$ & $(0.009)$ & $(0.008)$ & $(0.009)$ \\
\hline \multirow[t]{2}{*}{ avRisk } & & $-0.030^{* *}$ & $-0.048^{* * *}$ & & $0.067^{* * *}$ & $0.074^{* * *}$ \\
\hline & & $(0.015)$ & $(0.018)$ & & $(0.024)$ & $(0.022)$ \\
\hline \multirow[t]{2}{*}{ avFemale } & & $0.245^{* * *}$ & $0.242^{* * *}$ & & $-0.196^{* * *}$ & $-0.236^{* *}$ \\
\hline & & $(0.034)$ & $(0.058)$ & & $(0.062)$ & $(0.099)$ \\
\hline \multirow[t]{2}{*}{ avCRT } & & & -0.005 & & & -0.001 \\
\hline & & & $(0.040)$ & & & $(0.054)$ \\
\hline Observations & 192 & 192 & 144 & 192 & 192 & 144 \\
\hline $\mathrm{R}^{2}$ & 0.042 & 0.170 & 0.233 & 0.063 & 0.121 & 0.191 \\
\hline Adjusted $\mathrm{R}^{2}$ & 0.026 & 0.148 & 0.200 & 0.048 & 0.097 & 0.156 \\
\hline F Statistic & $2.714^{* *}$ & $7.627^{* * *}$ & $6.950^{* * *}$ & $4.230^{* * *}$ & $5.124^{* * *}$ & $5.401^{* * *}$ \\
\hline
\end{tabular}

Note:

${ }^{*} \mathrm{p}<0.1 ;{ }^{* *} \mathrm{p}<0.05 ;{ }^{* * *} \mathrm{p}<0.01$ 